\title{
Research on the Role Delineation of Government in Rural Pension Security in China
}

\author{
Sijia Yang \\ University of Electronic Science and Technology of China \\ Chengdu, China 611731
}

\author{
Zhen Zhang \\ University of Electronic Science and Technology of China \\ Chengdu, China 611731
}

\author{
Shanshan Li \\ University of Electronic Science and Technology of China \\ Chengdu, China 611731
}

\begin{abstract}
The social security system is an important symbol of social civilization. With the accelerated aging of the population in China and the change of rural family structure, the Chinese government has paid more attention to rural pension security and achieved remarkable results. However, it is worth noting that there are still many problems, such as the "lack of legal policy protection", "low efficiency of government participation" and "insufficient financial support" pointed out in this article. On this basis, it is necessary to scientifically position the role of the government in the rural pension security system so as to promote the sustainable development of Chinese social economy.
\end{abstract}

Keywords—pension security; role orientation; problem analysis

\section{INTRODUCTION}

With the decline in human fertility and the increase in life expectancy, the problem of population aging is becoming more and more serious. According to the data, "the population aged 65 and above in 2020 will reach 167 million people, accounting for $24 \%$ of the 698 million people in the world, which means that one of the four elderly people in the world is Chinese".[1] China is not only the largest populous country in the world, but also a large agricultural country. According to statistics, $43.9 \%$ of Chinese people live in rural areas.[2] However, the various hardware conditions in rural areas are not as good as those in cities and towns, and the uncompensated social security makes the government play a leading role, which makes it more important to study the role of the government in rural pension security.

\section{ANALYSIS OF THE STATUS AND PROBLEMS OF GOVERNMENT POSITIONING IN RURAL PENSION SECURITY IN CHINA}

Chinese social security system has undergone continuous reforms and has achieved remarkable results. At the same time, however, it is necessary to pay attention to the fact that rural pension security has always been a relatively weak link. There is a lack of a sound and effective pension security system, and farmers' pension needs have been difficult to meet for a long time.

\section{A. Basic Situation}

1) The number of elderly people has increased dramatically: In today's society, medical technology and quality of life are constantly improving, the medical environment is continuously optimized, the life expectancy of the population is prolonged, and the mortality rate of the population is continuously decreasing. With the increasing population, the elderly population has steadily increased, and the rate of growth has become faster and faster. The problem of aging population has also become more prominent. According to the results of the fifth census in China, China entered an aging society in 2000, and the family planning policy has promoted the acceleration of the aging society in China to a certain extent. "China is not only the most populous country in the world, but also the country with the largest population in the world, and the age structure of the population is becoming more and more obvious in various regions. China has entered an aging society."[3]

2) The scale of rural households decreases: The traditional rural elderly pension in China depends on the family elderly pension. Since ancient times, there has been an old saying of "raising children to provide against old age", the family elderly pension has an important place in the rural elderly pension security. However, since the implementation of family planning policy in 1970s, more and more single child families have emerged, and the scale of rural households decreases. In addition, the pace of urbanization in China has accelerated, and a large number of young and middle-aged laborers have left the countryside, and the role of land security has weakened. The reduction in the number of children in the family, coupled with the loss of young and middle-aged labor, the increase in the number of rural left-behind people, and the fact that most of them are composed of children and the elderly, coupled with the existence of the concept of "attaching importance to young children and ignoring the elderly", children are more valued than the elderly. The small scale of the family has directly led to great difficulties for 
rural family pensions, and the complex problems have become more acute.

3) Large disparities in urban and rural security: The implementation of the elderly security system in China is far worse in rural areas than in urban areas. Although the establishment of the minimum subsistence security system, medical aid and other forms of subsidies, but because of the lack of financial investment, it is difficult to meet the needs of farmers. For example, the rural medical insurance system stipulates that the funds to be provided by the local governments and the collective can not basically be provided. The reality is that most medical funds must be paid by the peasants themselves and lack the necessary medical protection. There are not a few cases in which the disease in old age causes poverty in the entire family. Rural population accounts for more than urban population, but all kinds of conditions lag behind urban areas. The difference between urban and rural dual structure leads to huge differences between urban and rural security.

\section{B. Existing Problems}

1) Lack of legal policy guarantee: The legislation speed of rural elderly security in China is obviously lagging behind the demand of social and economic development. However, many works must be carried out in accordance with certain laws and regulations, which bring great difficulties to the work of the government. First of all, it is worthy of recognition that the government has introduced the relevant laws on rural elderly security, but it does not explain the boundaries of responsibility and forms of responsibility, it also lacks compulsory, and there are problems such as low legislative level and chaotic subject. The lack of legislation directly leads to a series of problems in rural endowment insurance. There are certain deviations in the laws and regulations and social actual conditions, and it can not be adapted to local conditions to solve the problem of elderly security in specific regions. Furthermore, legislation needs to be prioritized, and laws and regulations need to be raised before the problem arises, rather than rushing to enact relevant laws after the problem arises. China is now in an important period of social reform and needs a stable social environment, which urgently requires the government to introduce policies related to rural pension security to ensure the orderly implementation of work.

2) Government participation is inefficient: The government of China is the leader of social endowment security. Summarizing the actual situation of each country, it can be seen that the government must shoulder the direct responsibility of social security whether it is directly sponsored by the government or undertaken through other subjects in the form of state guarantees.[4] The local governments lack specific supervision and have certain arbitrariness in the process of formulating policies. Therefore, the services of governments in different regions are not the same.[5] The government "covers all social security affairs" with a good starting point, but this just results in insufficient implementation of the policy, which in turn is not conducive to improving government efficiency. It is necessary to recognize that the development level of different regions in China is not balanced. When the construction of new rural areas in some areas has begun to take shape, there are still many rural developments that are still lagging behind, and it is very difficult for farmers to pay for themselves.[6] The implementation of elderly security requires the active support of farmers, but subsidies usually cannot keep up with the speed of economic development. Farmers are discouraged from facing huge amounts of insurance, and it is unrealistic to rely on government subsidies.

3) Inadequate financial support: Financial support and rural social security are interdependent and mutually reinforcing. Adequate financial funds are the strong backing for implementing relevant policies. However, in recent years, the social security gap in China has been expanding year by year, but the public still believes that social pension security is only a "government affair", making the government unwittingly become an "omnipotent manager" and almost taking all the investment risks and inefficiency. Rural elderly are mostly empty nesters, and they need great financial support and subsidies. Although the government has raised the pension standard, it is far from enough to compare the huge amount of funds needed. In countries with higher social security in the world, the proportion of social security funds accounts for a large share of their fiscal revenue. The existence of the dual structure of urban and rural areas in China has also led the government to invest more funds in urban areas, and the allocation of fiscal funds is somewhat unreasonable. There is also an inadequacy in the division of powers and responsibilities between the central and local governments. The degree of matching between the two is insufficient. In some places, local governments are required to increase their efficiency, rather than relying solely on the central government to contribute capital.

\section{CORRECTLY DEFINE THE ROLE OF GOVERNMENT IN RURAL ENDOWMENT INSURANCE}

\section{A. Strengthening Relevant Legislative Work}

China lacks corresponding law of rural pension security, which brings great difficulties for Chinese government to organize and implement the next step. Another country with a more serious problem of aging, Japan, has enacted the relevant laws and regulations such as the Life Protection Law and the National Health Insurance Law when solving the problems of social pension security. If Japan has made remarkable achievements in pension security, one of the reasons is that there is a relatively sound legal security, and the Chinese government should draw useful experience from it. At the same time, strengthen the popularization of rural pension security, so that the public realize that social pension security is not just a matter of government, they should share responsibility and risk with the government. Social forces have also been gradually incorporated into the pension system. The 
State Council executive meeting held in August 2013 called for "exerting market vitality and promoting social forces to become the protagonist of the pension service industry." It is estimated that by 2020 , the related work of the pension service industry will be greatly improved. $90 \%$ of the townships and more than $60 \%$ of the rural communities will establish pension institutions. In 2014, China established a unified basic elderly pension system for urban and rural residents. The purpose of this measure is to try to break the dual structure between urban and rural areas and try to achieve a balance between urban and rural areas, demonstrating the determination of the government to solve the existing problems in rural elderly security.

\section{B. Increasing Capital Investment}

For a long time, there has been insufficient investment in social security. Among them, the social pension insurance and unemployment insurance fund payment is difficult, and the gap needs to be supplemented by the state finance. The Chinese government is expected to establish a security system covering the entire population by 2020 , which requires 5740 billion yuan of funds, which can only be met if the proportion of social welfare spending increases to over $9 \%$ of Chinese GDP.[7] All of this means that the government needs to invest more money and energy. In particular, it is possible to establish a more standardized and reasonable subsidy mechanism, provide different forms of subsidies to the elderly in different regions, increase financial incentives for elderly institutions, improve various supplementary supply methods, and reduce the individual burden on the elderly. However, it should be noted that it is not entirely possible for the government to arrange it. The fiscal deficit of China already exists. If there is no bottom-line investment, it will eventually have very serious consequences for the national finance. The government can change the way of thinking. While appropriately increasing capital investment, it should focus on developing the rural economy and promoting the process of agricultural modernization. This can directly reduce the difficulties borne by farmers and increase their savings.

\section{Guiding the Society to Actively Participate}

The failure of the market and the non-profit of public goods all determine that the government is the leader of rural pension security. But the government is not omnipotent. Only when the government, the market, the enterprise and even the individual are responsible for the social security of the aged, can the healthy and orderly development of the society be promoted. The introduction of the participation of the market, enterprises, and other subjects can solve the problem of low efficiency and insufficient funds in the government. It can be handled by other subjects in areas that the government cannot handle. Conversely, the government should be responsible. As the leader, the government also needs to be a participant. First, the government should increase support for enterprises, ensure market access, guide the healthy operation of social capital, and broaden the sources of funds while ensuring that market rules are legitimate and reasonable. Second, the government should vigorously support township and village enterprises. If township and village enterprises develop well, they can retain more labor for the rural areas and ease the pressure of family pensions. Young people can also take care of their families.
Finally, there are differences in the actual resource supply capacity of each region. This requires the government to adapt to local conditions and determine the level of participation in different regions.

\section{CONCLUSION}

The issue of people's livelihood in the "Twelfth Five-Year Plan" was highlighted. As the government pays more attention to people's livelihood issues, it is becoming more and more important to improve and optimize the rural elderly security. The government also plays an important role in leading, guiding and participating in social pension security. First, there is no doubt about the government' role of the leader; Second, the government should also act as a guide to enact corresponding legal policies to guide the sound development of the elderly security system, the government as a guide is reflected in the introduction of the market, enterprises, citizens and other entities involved in the old-age security system, together with efforts to establish a standardized and reasonable security system. Only correctly define the role of the Chinese government in rural endowment insurance, follow the principle of "government guidance, policy support, social participation, market promotion",[8] and establish a reasonable old-age care service system that combines the basic pension of the country with the broad participation of social forces. The elderly in rural areas are no longer helpless, and they can really enjoy their old age.

\section{REFERENCES}

[1] Liu Ping. Research on the Influence of Population Aging on China's Economic Growth [D]. Shandong University, 2013.

[2] At the end of 2015, the Total Population of Mainland China Reached 1.37 Billion Men and 33.66 Million More Than Women http://district.ce.cn/newarea/roll/201601/19/t20160119_8371613.shtml.

[3] Blue Book of China Urban Pension Index 2017.

[4] Chu Fuling. On the Role and Function of the Government in Social Security[J].Journal of Beijing Municipal College of Planning Labor Management,2002(3).

[5] Pan Mingqing, Gao Wenliang and so on. Test and Analysis of the Influence of Urbanization on Household Consumption in China[J].Macroeconomic Research,2014(1):118-125.

[6] Yin Wenjia, Wang Hailong. Government Responsibility in the Construction of New Rural Insurance System: Problems and Improvements --- Contemporary Economics, 2015(32): 101-103

[7] Long Yuqi. Achievements and Problems of China's Social Security Expenditure: [J]. Academic Forum, 2011 (5) .

[8] The Government Guides Social Participation to Jointly Improve the Old-age Security System in China_China Shandong Net http://news.sdchina.com/show/2151621.html. 